\title{
Detecting and Tolerating Faults in Switched Reluctance Motors
}

\author{
Loránd Szabó ${ }^{1}{ }^{* *}$, Rareș Terec ${ }^{1}$, Mircea Ruba ${ }^{1}$, Pavol Rafajdus ${ }^{2}$ \\ ${ }^{1}$ Technical University of Cluj-Napoca, Department of Electrical Machines and Drives, Cluj-Napoca, Romania \\ ${ }^{2}$ University of Žilina, Department of Power Electrical Systems, Žilina, Slovak Republic \\ *Corresponding Author: Lorand.Szabo@emd.utcluj.ro
}

Copyright (C) 2013 Horizon Research Publishing All rights reserved.

\begin{abstract}
The switched reluctance motor (SRM) has inherently high level of fault tolerance. However despite of its high robustness and reliability it can face windings and bearings faults. The faults can cause costly downtimes in industrial environment, or they can bring about more severe consequences in safety critical applications. Therefore the detection of the faults in their incipient phase and the ability to tolerate them is a very important requirement for the electrical drive systems used in such applications. The paper deals with the most important faults of the SRMs, their effects on the machine performances and their detection. Also a reconfigurable fault tolerant control system for the SRMs is proposed, which is able to detect diverse winding faults and to mask these faults by imposing increased currents in the healthy remained coils of the machine. The fault detection capability and the correct reconfiguration of the proposed control system are proved by laboratory tests.
\end{abstract}

Keywords Switched Reluctance Motor, Winding Faults, Fault Detection, Fault Tolerance.

\section{Introduction}

The switched reluctance motor (SRM) is a double salient electrical machine with a passive rotor (see Figure 1).

Its stator is manufactured of punched laminations bonded into a stack. The rotor, made also of conventional laminations, is passive, having no windings, excitation, squirrel-cage or permanent magnets [1,2]. A phase winding comprises two coils placed on opposite poles connected in series. The excitation must be a sequence of current pulses applied to each phase in turn.

Its operation is based on the variable reluctance principle [3]. The torque is produced by the tendency of the rotor to reach a position where the inductance and the flux produced by the energized winding are maximized. The control system requires rotor position information for an optimal phase excitation sequence $[4,5]$. Due to their very simple construction the SRMs are robust and reliable, therefore they are ideal for safety-critical applications (aerospace, automotive, defense, medical, etc.) where it is desirable that the electrical drive system to be fault tolerant [6].

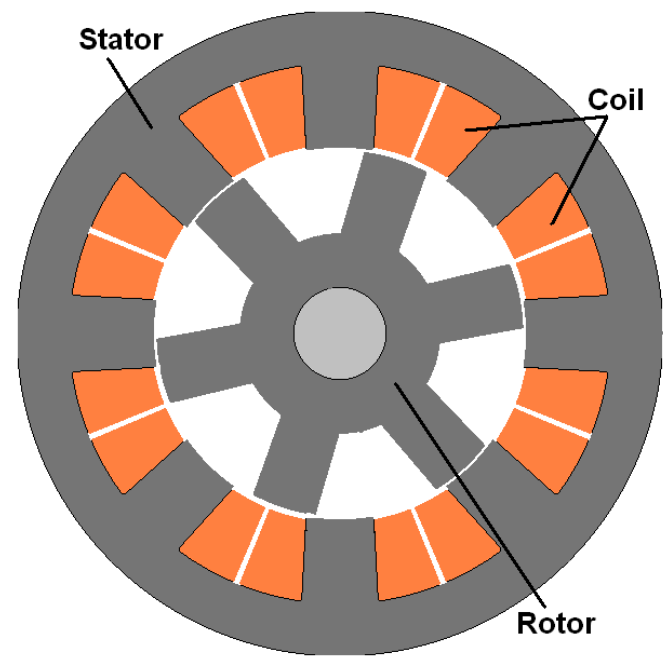

Figure 1. The switched reluctance machine

Unfortunately despite their robustness and reliability faults can appear during they exploitation. Therefore it is very important to detect a fault in its incipient phase in order the operator to be able to make the correct decision function of the effects of the fault on the entire system [7, 8]. In more advanced and important systems it is important that the entire electric drive system based on a SRM to be fault tolerant $[9,10]$. This means that the system has to be able to self detect the fault and to act upon the control of the motor in a manner to minimize the negative effects of the fault. Such systems are used in various safety-critical applications from diverse areas, like aerospace, military, automotive, medical, etc. [11-13]. The SRMs used in such applications has to be fed from power converters having also fault tolerant capabilities, and respectively they has to be controlled by systems that can auto-reconfigure if a fault is detected in the machine or in the power converter.

In the paper a short survey on frequent SRM faults and their detectors is presented. By means of numeric field 
computations the effects of faults on the SRM's performances are analyzed and also the effectiveness of the flux differential detector is studied. In the last part of the paper a reconfigurable fault tolerant control system for SRMs is proposed and tested by means of measurements.

\section{Faults of the SRM}

The SRM being a simple and robust machine practically only its windings and bearing can be faulted $[14,15]$. The windings of a SRM can face several defects [16]:

1. short circuit in one coil of a phase

2. a whole coil is bridged by a short circuit

3 . the whole phase is short circuited

4. open circuit in one coil of a phase

5. a short circuit between two different phases

6. a short circuit from one winding to ground.

These faults may be caused by mechanical vibration, heat, age, damage during installation, power converter fails, etc.

The bearings are subject to excessive wear and damage caused by inadequate lubrication, asymmetric loading or misalignment [17].

To avoid the harmful effects of faults it is necessary to detect them in their incipient phase [18].

\section{Fault Detectors for SRMs}

The winding faults of the SRM can be sensed by several failure detectors [19].

One of the most simple fault detection devices is the over-current detector given in Figure 2 [20]. Its efficiency is limited due to insufficiently fast response time and the inability to detect all types of faults.

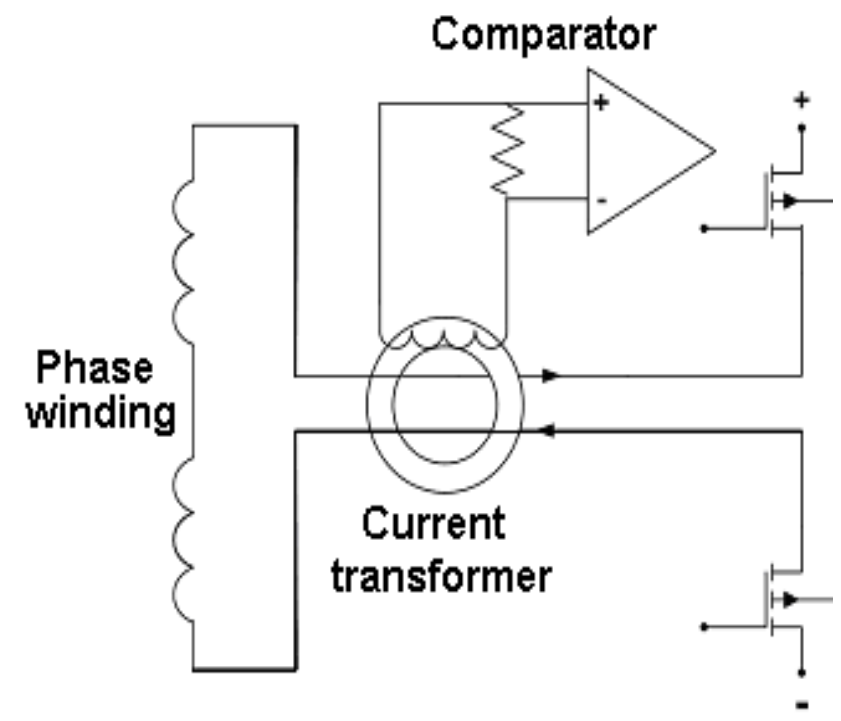

Figure2. The current differential detector

Another simple detector, the flux differential one, is shown in Figure 3.

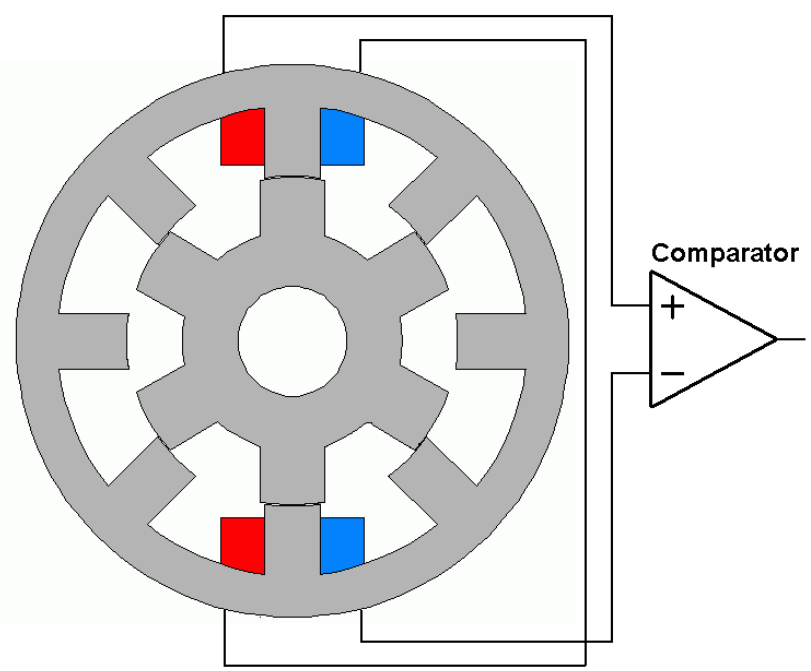

Figure 3. The flux differential detector

It requires additional search coils wrapped around the stator poles. The search coils of each phase are connected in series opposing, similarly to the connections of the main coils of the machine. During normal operation (without winding faults) the voltages induced in the two search coils are equal and opposite. Hence zero voltage will be at the input of the comparator. When a winding fault occur the imbalance in the pole fluxes induces different voltages in the two search coils. This voltage difference can be detected with the bidirectional comparator.

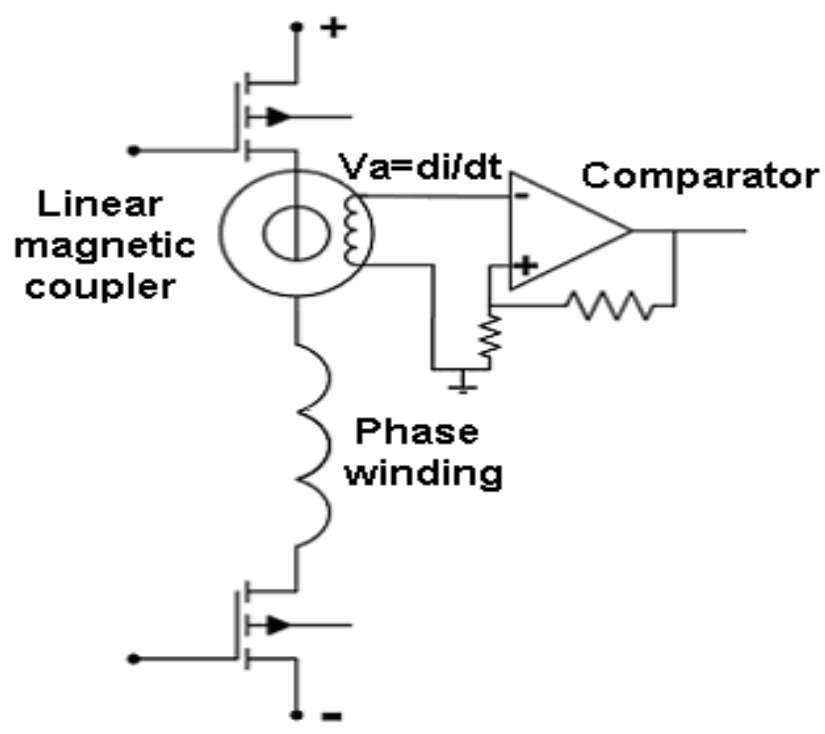

Figure 4. The rate-of-rise detector

The flux differential detector can sense ground faults, phase-to-phase faults and also short circuits, which cannot be detected by the previously presented over-current detector. Therefore this circuit seems to be the most adequate in almost all of the cases. Its main drawback is the requirement of the search coils, which cannot be placed on an already existing commercial SRM. But when designing SRMs for high fault tolerant systems the search coils can be relatively 
easily included in the machine.

Relatively more complicated is the rate-of-rise sensing detector. It consists of a linear magnetic coupler placed around the upper coil of the phase lead with the core, as shown in Figure 4.

The output voltage of the linear coupler is proportional to the time-rate-of-change of the phase current, which is modified due to winding faults [20].

Taking into account the ratio of performance over cost the flux differential detector seems to be the best solution for advanced fault tolerant systems [21]. The effectiveness of this detector was studied by means of finite elements analysis (FEA).

\section{FEA of the Faulty SRM}

All the winding faults of a SRM cause unsymmetrical field distribution inside the machine [22]. The best way to emphasize these changes is to perform a precise numeric field analysis of the SRM.

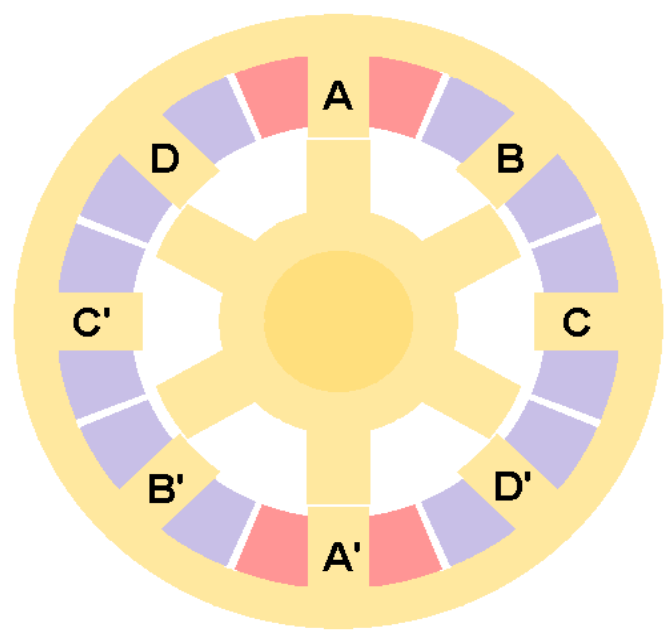

Figure 5. The cross section of the simulated SRM

The nameplate data of the simulated $8 / 6$ poles SRM are: $350 \mathrm{~W}, 300 \mathrm{~V}, 6 \mathrm{~A}, 600 \mathrm{r} / \mathrm{min}$.
The cross section of the motor together with its pole notations is given in Figure 5.

The FEA was performed by means of Flux 2D [23]. The simulated conditions of the machine were:

1. healthy machine

2. coil A with $20 \%$ of turns shorted

3. coil A with $50 \%$ of turns shorted

The most significant results for the machine conditions taken into study are given in Figure 6. The obtained flux lines are shown for the $A$ stator pole being aligned, half-aligned and unaligned relatively to the rotor poles.

As it can be clearly seen in these plots the symmetry of the magnetic flux distribution is more and more lost as the severity of the faults (the number of the shorted coils) is increasing. As the flux density in pole $A$ is lowering with the increase of the shorted turns also the torque development capability of the SRM is decreasing. The mean value of the developed torque during a displacement from the aligned to the unaligned position in the case of the healthy SRM is $3.41 \mathrm{~N} \cdot \mathrm{m}$. When $20 \%$ of the turns of one coil are shorted the torque development capability of the motor is reduced by $15 \%$ to $2.92 \mathrm{~N} \cdot \mathrm{m}$. When only half of $A$ coil's turns are working the developed torque is $65 \%$ of the healthy machine's one $(2.22 \mathrm{~N} \cdot \mathrm{m})$.

The developed FEA model was also applied for analyzing the behavior of the flux differential winding fault detector. Hence the the EMF induced in the 100 turns search coil versus the angular position of the rotor is given in Figure 7.

As it was expected also the induced EMF is strongly dependent of the fault severity.

Based on the simulated results it was possible also to compute the voltage differences between the EMFs induced in two search coils from opposite poles ( $A$ and $A^{\prime}$ ). This voltage difference is practically sensed by the flux differential detector. In Figure 8 the input of the detector is plotted versus the angular position of the SRM for three conditions of the coil from pole $A$.

The results shown in Figure 8 confirm the accurate sensing capability of this detector. The voltages of hundreds of $\mathrm{mV}$ at the input of the operational amplifier are enough for an efficient detection of the winding faults. 
Aligned poles $\left(\theta=0^{\circ}\right)$
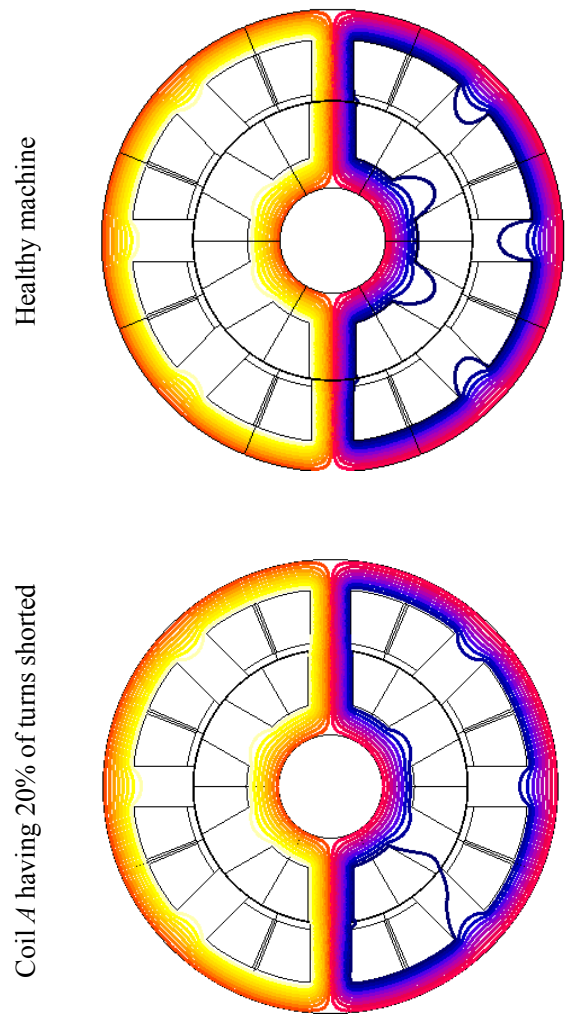

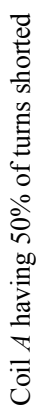

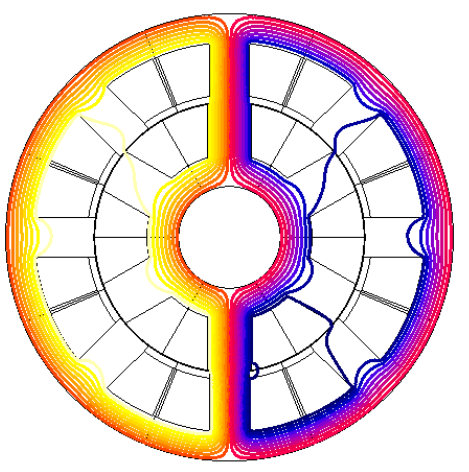

Half-aligned poles $\left(\theta=15^{\circ}\right)$
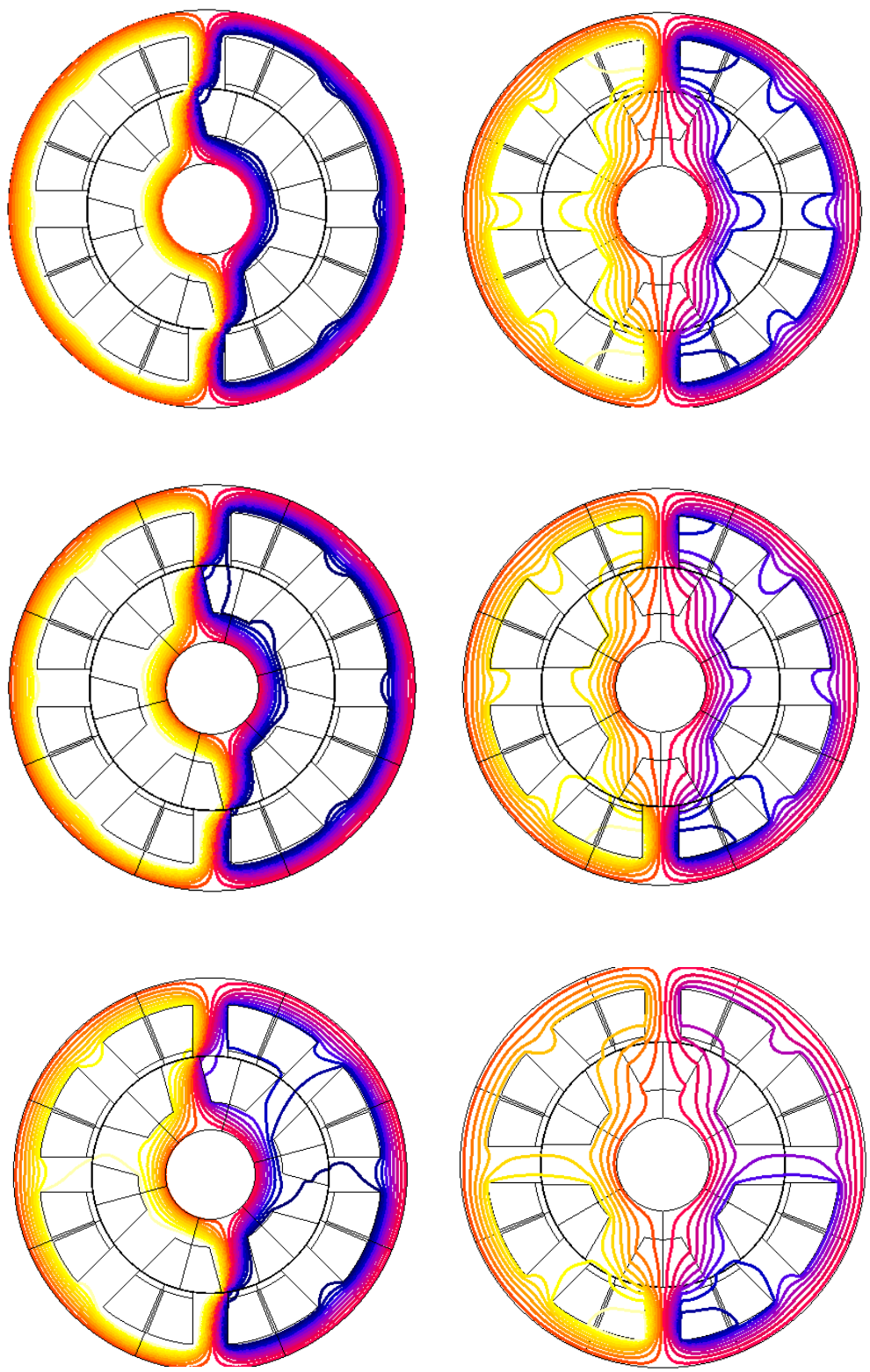

Figure 6. The results of the FAE 


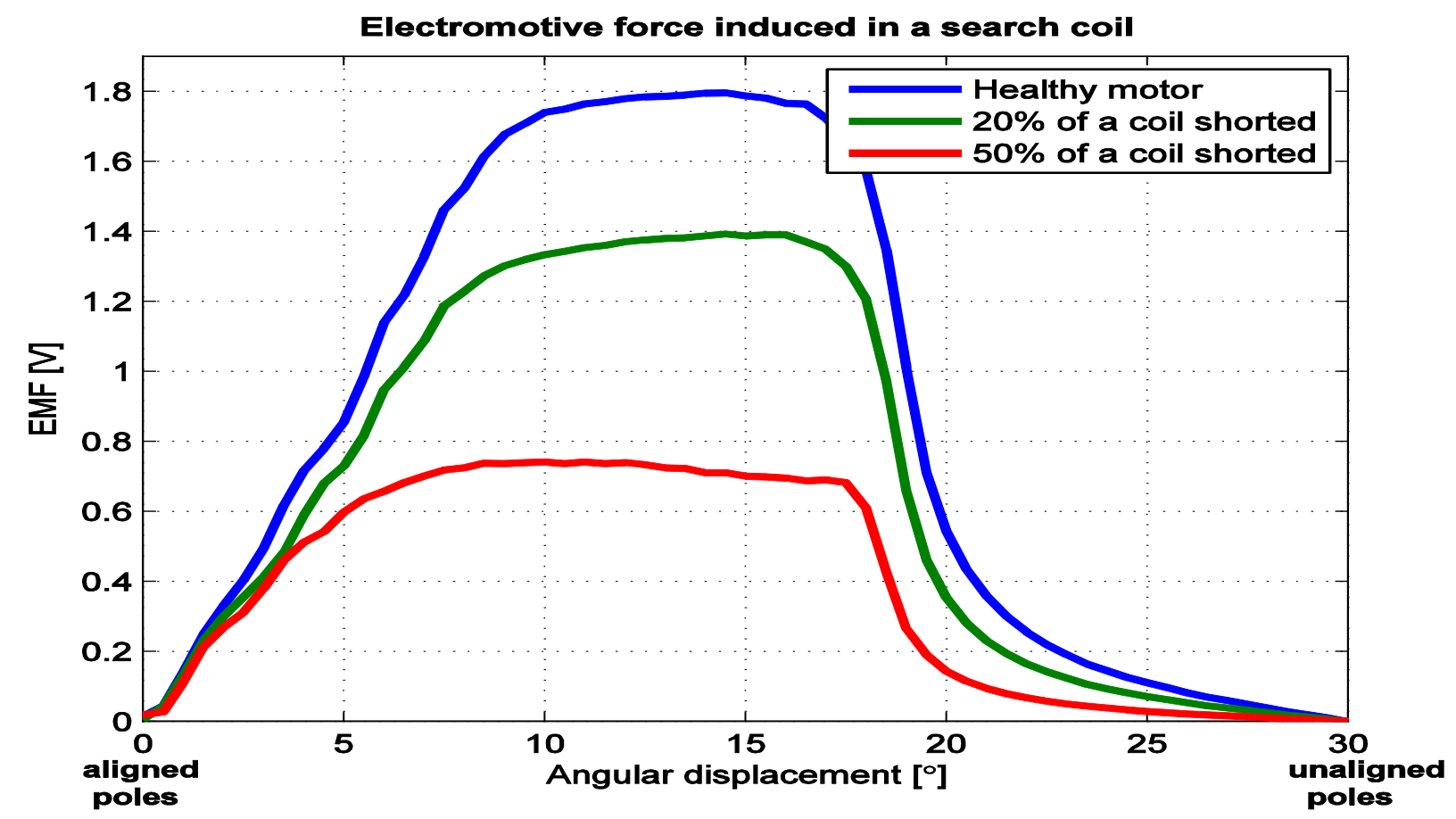

Figure 7. The EMF induced in the search coil from pole $A$
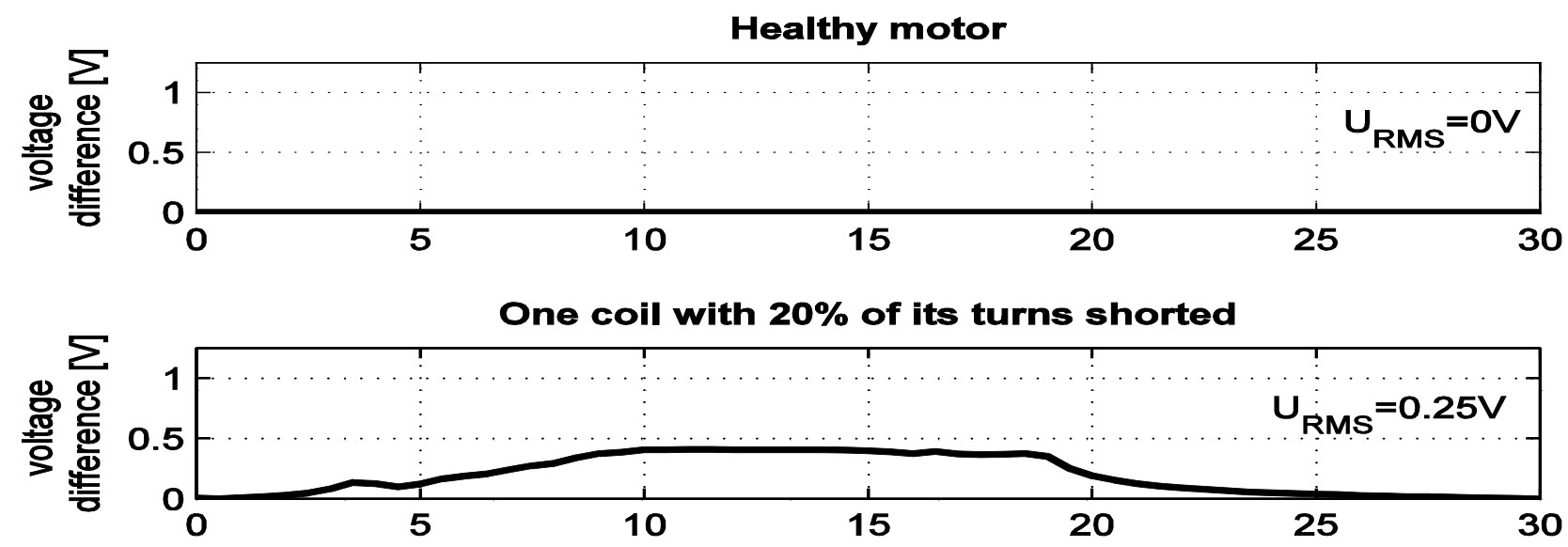

One coil with $50 \%$ of its turns shorted

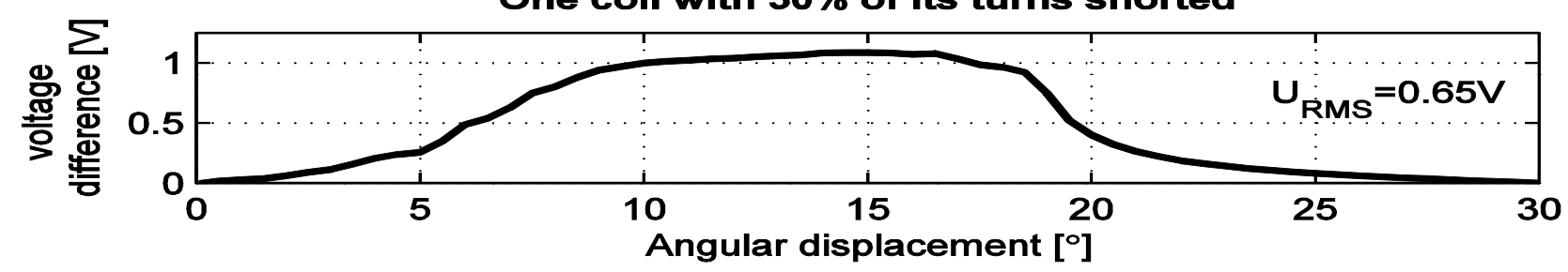

Figure 8. The input of the flux differential winding fault detector plotted versus the angular displacement

\section{The Fault Tolerant Control System}

The reliability of the SRM can be improved by controlling it by a fault tolerant system. The block scheme of such a system is given in Figure 9. Its main units are a computer (PC), two microcontroller boards (of PIC 18F4550 and dsPIC 30F6015 type), analog-to-digital converters (ADC), an inverter, the SRM to be controlled having an incremental position transducer (encoder) on its shaft and current sensors. 


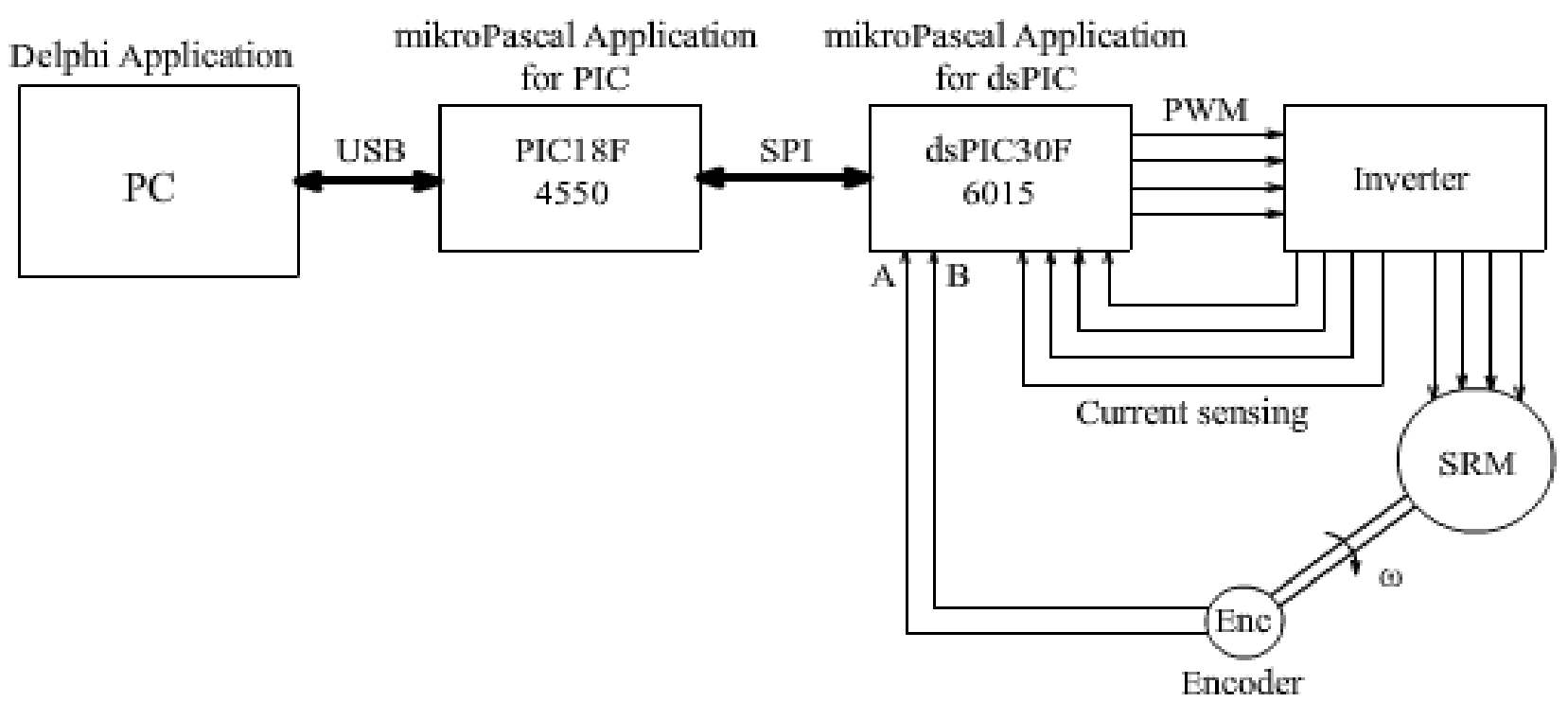

Figure 9. The fault tolerant control system of a SRM

On the basis of the control system two microcontrollers (PICs) stand [24]. The "brain" of the entire control system is the Controller Module featuring a dsPIC 30F6015 microcontroller (see Figure 10). The dsPIC has advanced specific motor control abilities being capable to handle a quadrature position encoder and 4 PWM channels [25]

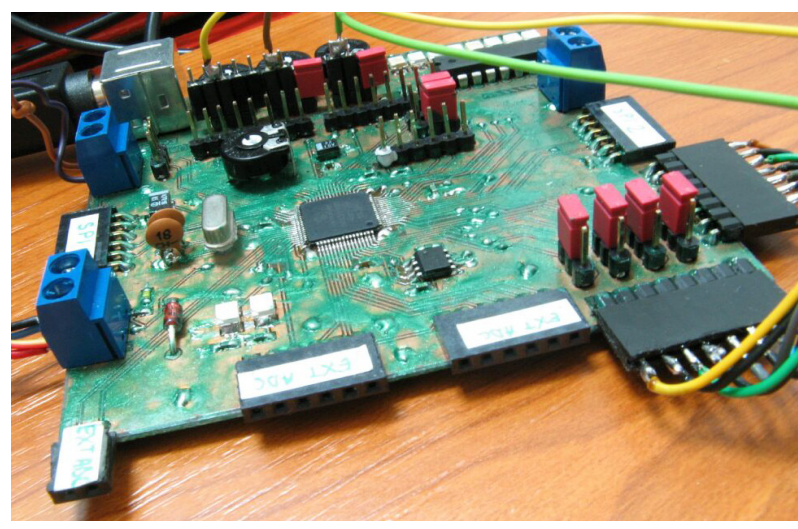

Figure 10. The Controller Module

As this dsPIC do not feature USB connection an intermediary microcontroller of PIC 18F4550 type (without digital signal processing capabilities) is communicating between the computer and the Controller Module.

The reconfigurable fault tolerant control system was implemented by using several programming environments. The main part of the control program is the graphical user interface (GUI) given in Figure 11. It is developed in Delphi, which is a set of object-oriented extensions to standard Pascal program [26].

All the settings of the control system can be performed by the user via this friendly GUI: the selection of the communication port, of the Serial Peripheral Interface (SPI) speed required to run the connectivity between the Interface Module and the Controller Module, of the applied current control method, of the coefficients of the PID controller, respectively of the speed, angle offset, dead time and pre-offset adjustments of the motor, etc.

From the GUI, the measured currents and the actual speed of the machine can be red and the condition of the coils can be followed, too.

The code of the Interface Module program was written in mikropascal, a variant of Pascal for microcontrollers. The PIC module is programmed in order to facilitate the connection between the PC and the dsPIC module at high speed via USB 2.0. The code features a USB library that handles all the necessary commands between the Controller Module and the GUI.

Once the USB connection has been established, the PIC, with its specific ports configured through a program, enables a USB interrupt procedure (necessary for the transfer) and activates a debug feature by means of an on-board LED, found on the Interface Module board. Afterwards, the SPI parameters are configured for master speed, idle configuration and clock idle. The main program deals with the bytes sent back and forth from the PC to the Controller Module, making sure no information is being lost in the process [26].

The program of the Controller Module was also written in mikropascal, and acts as an interpreter of the commands sent from the Delphi application, and a series of procedures act upon identifying the desired response. It is divided into separate units for a more comprehensible approach, but also to allow them to be used by other programs as well. The project automatically creates a series of setting files and windows related libraries.

The main unit of the program, called MotorController6015RealEnc, handles all the data sent from the GUI, checks which action code has been sent and calls the appropriate function for it. It also ensures that all the protocols have been enabled, that the SPI communication is active and enables a loop in which all the main control procedures remain active. 


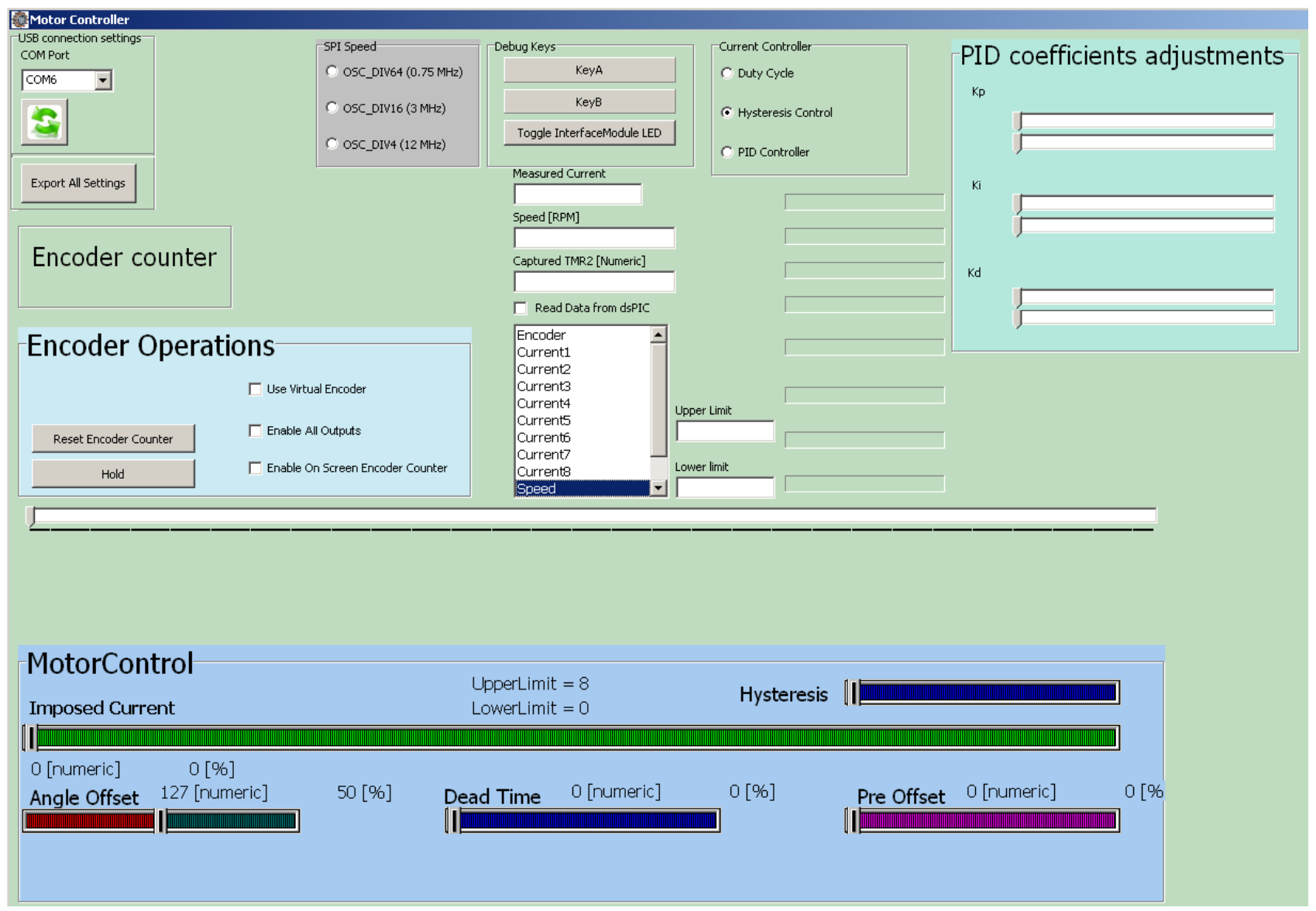

Figure 11. The GUI of the control system

Several other units had been programmed, as the SPI Interface, which deals with the initializations regarding the SPI protocol and the interrupts required for the communication, the PinsDeclaration, which configures the pins of the dsPIC, the MCP3001Controller, which handles the ADC actions, the Encoder decoding the signals from the SRM encoder, the PosController dealing with the angle processing and the SRM phase distribution of the current impulses or the MCPWM4Ph, which handles the PWM motor control method [27].

The implemented control strategy is a fault tolerant one. Its first task is to detect the winding faults. For this purpose, the current sensors used for the current control were employed. A threshold of at least $20 \%$ of the machine's rated current was established. If the measured current is under the threshold, the corresponding coil is considered to be a faulty. As a fault is detected, starting from the next revolution an adequate reconfigured control strategy is activated.

The opened coil faults lead to a decrease in torque and speed of the SRM, since the torque generation is directly proportional to the number of working coils, as it was demonstrated in [28].

It was also concluded that by increasing the current in a part of the healthy remained coils, the effects of the winding faults can be partially compensated.
Upon the type of the detected winding faults the proposed control system is able to reconfigure its control strategy upon three scenarios:

1. If only a single coil is opened the current in the other coil of the same phase is increased by approximately $20 \%$.

2. If two coils from different phases are detected as faulted the other two coils of the corresponding phases are increased by the same amount of current.

3. If an entire phase is opened (both coils opened of the phase) an increased current of around $20 \%$ is imposed in the previously supplied phase to the faulty one. The selection of this phase is function of the sense of rotation. All the other healthy remained coils are supplied with $10 \%$ greater currents.

In all these cases it is expected that the rotation of the SRM to be continued despite the faults. Of course the torque ripples in these faulty conditions will be higher.

It should be mentioned that the proposed reconfigurable control system can be applied only for the motors which were designed to work at $120 \%$ of their rated current.

6. Testing the Control System

To test the developed SRM fault tolerant control system an advanced laboratory setup shown in Figure 13 was built [29]. 
Currents in the first coils of each phase
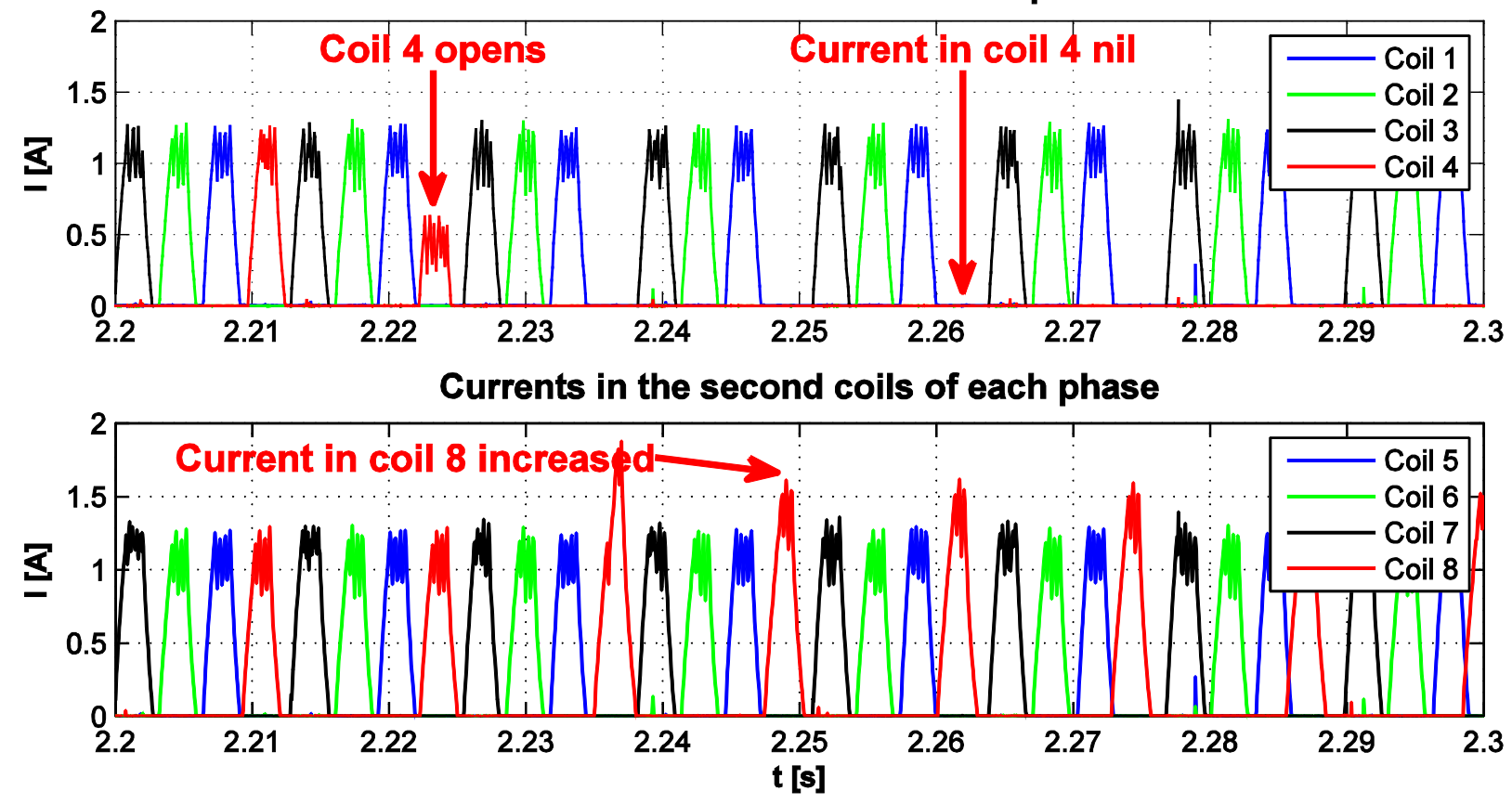

Figure 12. The current waveforms during the control system reconfiguration

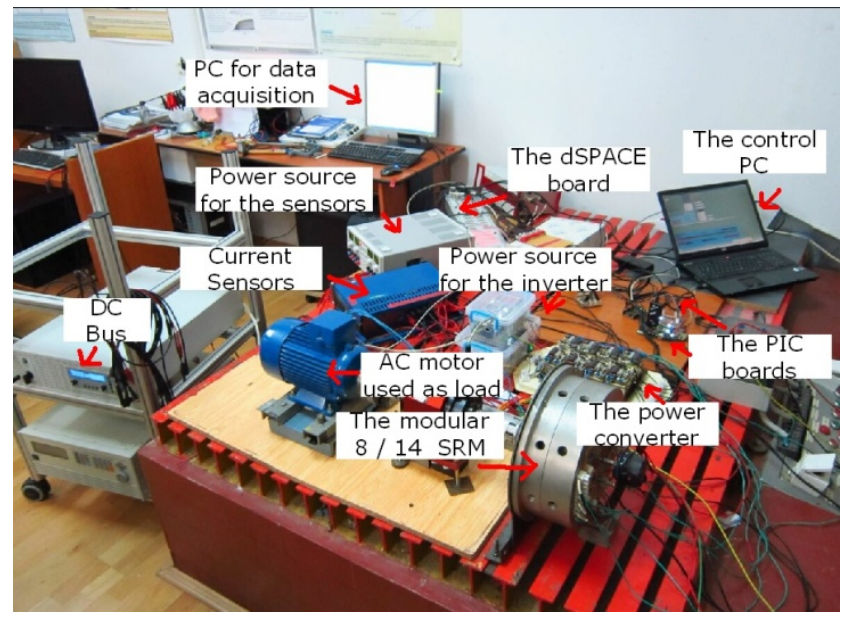

Figure 13. The laboratory test bench

It consists of the control system (the Interface and the Controller modules), a personal computer to run the Delphi application, a special built four-phase 8/14 SRM (having all its coils fed separately from an eight-phase $300 \mathrm{~V} / 10 \mathrm{~A}$ /phase, modularly built inverter), a 1XP8001 type Siemens encoder mounted on the shaft of the SRM, an induction machine for loading the SRM, a power supply for feeding the dc bus of the inverter, another source for the current sensors, and a third one for the dsPIC microcontroller system, the PIC microcontroller and the ADC boards.

The nameplate values of the SRM are: $350 \mathrm{~W}, 300 \mathrm{~V}$ and 6 A. It is capable to develop a rated torque of $5 \mathrm{~N} \cdot \mathrm{m}$.

The special fault tolerant SRM was specially designed to work also at currents $33 \%$ greater than the rated value (up to 8 A) without overheating.

Two ADC boards were used. The first one has 8 ADCs for each of the 8 currents of the machine. The other board was used for signal reconditioning in order to maintain the command signals as close as possible to the $5 \mathrm{~V}$ requirements.

For the real time current acquisitions a dSPACE ACE1103 development system was used, which can acquire separately the currents of all the 8 coils of the controlled SRM.

The measured currents were both displayed on-line by using the Control Desk application of the dSPACE system and saved on the hard disk of the PC for graphical postprocessing in MATLAB.

The laboratory measurements were performed at $300 \mathrm{r} / \mathrm{min}$ speed and $0.5 \mathrm{~N} \cdot \mathrm{m}$ load torque for four conditions of the modular SRM:

1. the healthy machine

2. one opened coil fault

3. two opened coils faults (from different phases)

4. one opened phase fault.

From the numerous results obtained during the tests the most significant ones given in Figure 12 were chosen.

As it can be seen in the plots after about $2.22 \mathrm{~s}$ coil no. 4 opens and its current become nil. The control system senses the fault and imposes an increase by $20 \%$ of the current in the other coil (no. 8) of the same phase.

The presented results confirm the correct operation of the reconfigurable fault tolerant control system in discussion.

\section{Conclusion}

The fault tolerance is an obligatory issue for all the equipment used in safety critical industrial applications. In 
the paper a survey on the most common SRM faults and on the devices able to detect them is presented.

By means of FEA the effects of faults on the machine's performances and the most widespread fault detector circuit were studied.

In the second part a reconfigurable fault tolerant control system for the SRMs is proposed and the results of the laboratory tests are detailed. All the obtained results emphasize the correct work of the control system both in healthy condition and having diverse winding faults.

\section{Acknowledgements}

This work was partially supported by the Romanian Executive Agency for Higher Education, Research, Development and Innovation Funding (UEFISCDI) under the Automotive Low-Noise Electrical Machines and Drives Optimal Design and Development (ALNEMAD) Joint Applied Research Project (PCCA) in the frame of "Partnerships" projects (PN II - National Plan for Research, Development and Innovation).

\section{REFERENCES}

[1] R. Krishnan, Switched Reluctance Motor Drives: Modeling, Simulation, Analysis, Design, and Applications. Boca Raton (USA): CRC, 2001.

[2] A. Bentounsi, R. Rebbah, H. Djeghloud, S. Belakehal, H. Benalla, and B. Batoun, "Design and modeling of a doubly salient variable reluctance machine," in Proceedings of the 18th International Conference on Electrical Machines (ICEM '2008) Vilamoura (Portugal), 2008.

[3] G. Henneberger and I. A. Viorel, Variable Reluctance Electrical Machines. Aachen (Germany): Shaker Verlag, 2001.

[4] T. J. E. Miller, Electronic Control of Switched Reluctance Machines. Oxford (U.K.): Newnes, 2001.

[5] H. C. Chang, C. H. Chen, Y. H. Chiang, W. Y. Sean, and C. M. Liaw, "Establishment and control of a three-phase switched reluctance motor drive using intelligent power modules," IET Electric Power Applications, vol. 4, pp. 772-782, 2010.

[6] L. Szabó and M. Ruba, "Segmental stator switched reluctance machine for safety-critical applications," IEEE Transactions on Industry Applications, vol. 48, pp. 2223-2229, 2012.

[7] R. Krishnan, R. Arumugan, and J. Lindsay, "Design procedure for switched-reluctance motors," IEEE Transactions on Industry Applications, vol. 24, pp. 456-461, 2002.

[8] T. Raminosoa, B. Blunier, D. Fodorean, and A. Miraoui, "Design and optimization of a switched reluctance motor driving a compressor for a PEM fuel-cell system for automotive applications," IEEE Transactions on Industrial Electronics, vol. 57, pp. 2988-2997, 2010.
[9] M. Blanke, Diagnosis and fault-tolerant control. Berlin (Germany): Springer Verlag, 2003.

[10] M. Ruba, I. Bentia, and L. Szabo, "Novel modular switched reluctance machine for safety-critical applications," in Proceedings of the 19th International Conference on Electrical Machines (ICEM '2010) Rome (Italy), 2010, pp. $1-6$.

[11] M. Zhang, Z. Liu, C. Morisset, and A. Ravn, "Design and verification of fault-tolerant components," Methods, Models and Tools for Fault Tolerance, pp. 57-84, 2009.

[12] N. H. El-Farra and A. Armaou, "Fault-tolerant process control," International Journal of Robust and Nonlinear Control, vol. 22, pp. 1-2, 2012.

[13] C. W. Johnson, Failure in Safety-Critical Systems: A Handbook of Accident and Incident Reporting. Glasgow (UK): University of Glasgow Press, 2003.

[14] S. Nandi and H. A. Toliyat, "Condition monitoring and fault diagnosis of electrical machines - A review," in Proceedings of the IEEE International Conference on Electric Machines and Drives (IEMDC '99), Seattle (USA), 1999, pp. 197-204.

[15] T. J. E. Miller, "Faults and unbalance forces in the switched reluctance machine," IEEE Transactions on Industry Applications, vol. 31, pp. 319-328, 1995.

[16] B. Schinnerl and D. Gerling, "Analysis of winding failure of switched reluctance motors," in Proceedings of the IEEE International Electric Machines and Drives Conference (IEMDC '09), Miami (USA), pp. 738-743.

[17] ***. Care and maintenance of bearings. Available: http://www.ntnamerica.com/pdf/Other/3017cat.pdf

[18] H. Vasquez and J. K. Parker, "A new simplified mathematical model for a switched reluctance motor in a variable speed pumping application," Mechatronics, vol. 14, pp. 1055-1068, 2004.

[19] A. Arkadan, P. Du, M. Sidani, and M. Bouji, "Performance prediction of SRM drive systems under normal and fault operating conditions using GA-based ANN method," IEEE Transactions on Magnetics, vol. 36, pp. 1945-1949, 2000.

[20] C. M. Stephens, "Fault detection and management system for fault-tolerant switched reluctance motor drives," IEEE Transactions on Industry Applications, vol. 27, pp. 1098-1102, 1991.

[21] R. Terec, M. Ruba, L. Szabó, and E. Kovács, "Fault detection in switched reluctance machines," Journal of Computer Science and Control Systems, vol. 3, pp. 231-236, 2010 .

[22] R. Terec, I. Benția, M. Ruba, L. Szabó, and P. Rafajdus, "Effects of winding faults on the switched reluctance machine's working performances," in Proceedings of the 3rd IEEE International Symposium on Logistics and Industrial Informatics (LINDI '2011), Budapest (Hungary) 2011, pp. 143-148.

[23] ***, "Flux 2D - package for electromagnetic and thermal analysis using finite elements (user's guide)," ed. Meylan (France): CEDRAT, 2005.

[24] T. Wilmshurst, Designing Embedded Systems with PIC Microcontrollers: Principles and Applications. Oxford (UK): 
Newnes, 2006.

[25] S. Arslan, K. Köse, M. Engin, E. Z. Engin, and M. Korürek, "A design of DSPIC based signal monitoring and processing system," Journal of Electrical and Electronics Engineering, vol. 9, pp. 921-927, 2009.

[26] M. Cantù, Mastering Borland Delphi 2005. Indianapolis (USA): SYBEX, 2006.

[27] R. Gobbi and K. Ramar, "Optimisation techniques for a hysteresis current controller to minimise torque ripple in switched reluctance motors," IET Electric Power Applications, vol. 3, pp. 453-460, 2009.

[28] L. Szabó and M. Ruba, "On fault tolerance increase of switched reluctance machines," in Proceedings of the IEEE Region 8 EUROCON Conference (EUROCON '2009), St. Petersburg (Russia), 2009, pp. 734-739.

[29] R. Terec, "Development of a Fault Tolerant Control System for Switched Reluctance Motors," Ph.D., Electrical Machines and Drives Department, Technical University of Cluj, Cluj (Romania), 2012. 